Int. J. Electrochem. Sci., 14 (2019) 9150 - 9158

International Journal of

ELECTROCHEMICAL

SCIENCE

WWW.electrochemsci.org

Short Communication

\title{
Growth of Well-aligned Ag-doped ZnO Nanorods Arrays on FTO Substrate Using Electrochemical Approach: Optical Properties and Photocatalytic Activity
}

\author{
Li-li Wang*, Wei Ma, Ji-long Ma, Guo-quan Shao \\ Bozhou University, Bozhou Anhui 236800, China \\ *E-mail: 1lwang_89@163.com, 1lwang@mail.ustc.edu.cn
}

doi: $10.20964 / 2019.09 .81$

Received: 5 June 2019 / Accepted: 13 July 2019 / Published: 5 August 2019

\begin{abstract}
A simple electrochemical synthesis was successfully used for the growth of Ag-doped $\mathrm{ZnO}$ nanorods on fluorine-doped tin oxide to investigate the photocatalytic degradation activity. Photoluminescence (PL) spectroscopy and UV-Vis absorbance spectra at normal atmospheric conditions were used to examine the optical characteristics of the nanorods. Composition and morphology were investigated using energy-dispersive X-ray spectroscopy (EDX) and field emission scanning electron microscopy (FESEM). FESEM images show the synthesized Ag-doped $\mathrm{ZnO}$ nanostructures possess very highdensity rod-shaped morphologies. UV-visible spectroscopy indicates a red shift in absorption peaks centered at $376 \mathrm{~nm}$ for $\mathrm{Ag}$-doped $\mathrm{ZnO}$ nanorods in comparison to undoped $\mathrm{ZnO}$ nanorods. $\mathrm{Pl}$ results reveal that initially as the Ag doping is done, the vision emission intensity decreases. Photocatalytic analysis of the samples shows the degradation rate increases by doping $\mathrm{Ag}$ ions into $\mathrm{ZnO}$ lattice structures which show much higher photocatalytic degradation rates.
\end{abstract}

Keywords: Ag-doped $\mathrm{ZnO}$ nanorods; Electrochemical method; Optical properties; Photocatalytic activity

\section{FULL TEXT}

(C) 2019 The Authors. Published by ESG (www.electrochemsci.org). This article is an open access article distributed under the terms and conditions of the Creative Commons Attribution license (http://creativecommons.org/licenses/by/4.0/). 